\title{
Parental willing to take invasive diagnosis after Expanded Noninvasive Prenatal Testing (expanded NIPT) in a cohort of 24768 cases
}

\author{
Yunsheng Ge \\ Women and children's hospital \\ Jia Li \\ BGI \\ Jianlong Zhuang \\ Quanzhou women and children's hospita \\ Jian Zhang \\ Women and Children's Hospital \\ Yanru Huang \\ Women and children's hospital \\ Meihua Tan \\ BGI \\ Wei Li \\ BGI \\ Pi-lin Sung \\ Taipei Veterans General Hospital \\ Jiayan Chen \\ Women and Children's Hospital \\ Yulin Zhou ( $\nabla 2149657 @ q q . c o m$ ) \\ Women's and Children's Hospital https://orcid.org/0000-0002-0915-2372
}

\section{Research article}

Keywords: expanded noninvasive prenatal test, common trisomies, sex chromosomal aneuploidies, rare autosomal aneuploidies, copy number variations

Posted Date: April 23rd, 2020

DOI: https://doi.org/10.21203/rs.3.rs-21668/v1

License: (a) (i) This work is licensed under a Creative Commons Attribution 4.0 International License. Read Full License 


\section{Abstract}

\section{Background}

The main aims of the study were to investigate the performance of expanded noninvasive prenatal test (expanded NIPT) in screening for common trisomies, sex chromosomal aneuploidies (SCAs), rare autosomal aneuploidies (RATs) and copy number variations (CNVs) and parental willing to taking invasive prenatal diagnosis after expanded NIPT in China.

Results

Of the 24,736 cases, successful follow-up was conducted in $92.2 \%(411 / 446)$ cases. The sensitivity of expanded NIPT test was $98.61 \%, 90.91 \%$ and $100 \%$ and specificity was $99.91 \%, 99.95 \%$ and $99.87 \%$ for the detection of trisomies 21,18 and 13 respectively. Expanded NIPT detected 45, XO, 47, XXX, 47, XXY, XYY syndrome, RATs and CNVs with positive predictive values of $57.39 \%, 19.61 \%, 75 \%, 79.41 \%, 77.78 \%, 10 \%$ and $56.25 \%$ respectively. The women carrying fetuses with $\mathrm{T} 21 / \mathrm{T} 18 / \mathrm{T} 13$ underwent invasive prenatal diagnosis and terminated their pregnancies at higher rates than those positive for SCAs, RATs and CNVs.

\section{Conclusions}

Our study demonstrates that the expanded NIPT detects fetal trisomies 21,18 and 13 with high sensitivity and specificity. The accuracy of detecting SCAs, RATs and CNVs is still relatively poor and needed to be improved. With a positive expanded NIPT result, the women at high risk for common trisomies are more willing to take invasive prenatal diagnosis and terminate their pregnancies.

* the first two authors contribute equally to this study.

\section{Background}

Noninvasive prenatal testing (NIPT) was firstly introduced to screen for fetal trisomy 21 in 2011 and went globally rapidly [1]. Up to date, millions of NIPT tests have been conducted throughout the world, and the clinical performance of expanded NIPT to detect fetal trisomy 21 (T21), trisomy 18 (T18), trisomy 13 (T13) and SCAs are now well recognized [2-6]. In recent years, the test has been expanded to detect RATs and CNVs, however, there are few reports on the application of those expanded NIPT to the detection of RATs and CNVs [7-11]. Many factors affect the decisions to take further prenatal diagnosis, and to continue or terminate pregnancy, including the type of fetal disease, the level of prenatal genetic counseling, the quality of life of the pregnant woman, cultural factors, multiple cross-disciplinary approaches, etc [12]. On receiving different positive expanded NIPT results, it remains unclear the attitude of pregnant women towards invasive prenatal diagnosis and continuation of pregnancy. Therefore, a systematic review of expanded NIPT test results, diagnostic tests and pregnancy outcomes of all screening results is needed in a large-scale population, which allows for comprehensively evaluating the clinical performance of the test and parental willing to taking invasive prenatal diagnosis.

In the present study, we analyzed the clinical data of a cohort of 24,768 participants who underwent expanded NIPT tests at the Women and Children's Hospital from January 2013 to April 2019 in Xiamen of Fujian province, China. We reviewed the expanded NIPT results, the diagnostic invasive test results and clinical follow-up information to evaluate the performance of expanded NIPT in screening for trisomies $21,18,13$, SCAs, RATs and CNVs. We also retrospectively analyzed the clinical data of 533 pregnant women with positive expanded NIPT results and examined their clinical treatments, results of prenatal diagnosis and pregnancy outcomes. This study revealed expanded NIPT detected trisomies 21, 18, 13, 47, XXX, 47, XXY, XYY syndrome with a high true positive value but showed a relatively poor performance in detecting $45, \mathrm{XO}$, RATs and CNVs. The women at high risk for common trisomies are more willing to take invasive prenatal diagnosis and terminate their pregnancies. 


\section{Results}

\section{General characteristics of expanded NIPT test results}

A total of 24,768 cases were included in this study, the majority of the women came from the Fujian province, China. Of these samples, $0.14 \%$ (32/24768) were rejected for further processing owing to inadequate volume, contamination, low fraction of fetal DNA. The mean age of the remaining cases was 32.53 years old, $30.9 \%(7,639 / 24,736)$ cases were greater than 35 years old at the time of expanded NIPT tests. The gestational weeks ranged from 11 to 33 weeks, with a mean of 16.87 weeks. Of the 24,736 cases, $1.8 \%$ (446/24736) cases were found to be high risk for T21, T18, T13 and SCAs. Additionally, $0.22 \%$ (54/24736) and $0.13 \%$ (33/24736) cases were positive for RATs and CNVs respectively. The incidences of common trisomies, RATs and CNVs in the pregnant women with older maternal age ( $>=35$ years) were not significantly higher than those in the pregnant women with younger maternal age (<35 years) $[P=0.33,1.9 \%(197 / 10,337)$ VS $1.7 \%(249 / 14,399)$ for common trisomies; $P=0.41,0.25 \%(26 / 10,337)$ VS $0.19 \%(28 / 14,399)$ for RATs and $P=0.86,0.13 \%(13 / 10,337)$ VS $0.14 \%(20 / 14,399)$ for CNVs, fisher exact test].

\section{Expanded NIPT test results for T21, T18, T13 and SCAs}

The 446 high risk cases comprised 178 T21,51 T18,38 T13, 179 SCAs (82 XO, 25 XXX, 48 XXY, 24 XYY) pregnant women. 345 underwent amniocenteses. 142 T21, 30 T18, 9 T13 and 60 SCAs (10 XO, 9 XXX, 27 XXY, 14 XYY) cases were confirmed by karyotyping analysis (Fig. 1). 78.84\% (190/241) of the women chose to terminate their pregnancies. 17 women had live births, giving birth to 1 T21 baby and 16 babies with SCAs ( 3 XO, 2 XXX, 5 XXY and 6 XYY). 104 cases including 16 T21,9 T18,24 T13, 55 SCAs (41 X0, 3 XXX, 7 XXY and 4 XYY) with confirmatory testing results showed non-concordant karyotyping results. 25 cases chose to continue their pregnancies and gave normal live births. Four cases including two false negative cases of T21 and T18 were confirmed by karyotyping analysis and they opted for TOP (Table 1 and Fig. 1). The other 47 cases had no confirmed pregnancy outcomes (Fig. 1). Of 66 high-risk cases without confirmative invasive tests, 19 women chose termination of pregnancy (TOP), because of abnormal ultrasound findings or anxiety (Table 2 and Fig. 1). 10 cases lost pregnancies, due to fetal demise. 37 pregnant women continued their pregnancies and had normal live births with normal neonatal examination results and physical appearance at the time of postnatal follow-up (Fig. 1).

Table 1

Ultrasound findings and diagnostic testing results in pregnancies with false negative results

\begin{tabular}{|lllllll|}
\hline CaselD & $\begin{array}{l}\text { Gestational } \\
\text { week }\end{array}$ & $\begin{array}{l}\text { expanded } \\
\text { NIPT } \\
\text { Result }\end{array}$ & Ultrasound Result & Procedure & $\begin{array}{l}\text { Diagnostic } \\
\text { Testing } \\
\text { Result }\end{array}$ & $\begin{array}{l}\text { Pregnancy } \\
\text { Outcome }\end{array}$ \\
\hline 1 & $16 w+5$ & T21 & Normal & Amnio & $47, \mathrm{XN},+18$ & TOP \\
\hline 2 & $18 w+6$ & XO & Normal & Amnio & $47, \mathrm{XN},+18$ & TOP \\
\hline 3 & $13 w+2$ & Negative & Fetal demise & Amnio & $47, \mathrm{XN},+18$ & $\begin{array}{l}\text { Fetal } \\
\text { demise }\end{array}$ \\
\hline 4 & $14 w+2$ & $\mathrm{XXY}$ & $\begin{array}{l}\text { Fetal left choroid plexus } \\
\text { cyst }\end{array}$ & Amnio & $47, \mathrm{XN},+21$ & TOP \\
\hline 5 & $15 w+1$ & $\mathrm{XXY}$ & $\begin{array}{l}\text { Fetal left choroid plexus } \\
\text { cyst }\end{array}$ & Amnio & $47, \mathrm{XN},+21$ & TOP \\
\hline
\end{tabular}

Note: T21: trisomy 21, TOP: termination of pregnancy, amnio: amniocentesis. 
Table 2

Abnormal ultrasound findings in pregnancies without confirmed high-risk expanded NIPT results

\begin{tabular}{|c|c|c|c|c|c|}
\hline CaselD & Age & $\begin{array}{l}\text { Gestational } \\
\text { week }\end{array}$ & $\begin{array}{l}\text { expanded } \\
\text { NIPT } \\
\text { Result }\end{array}$ & Abnormal ultrasound Result & $\begin{array}{l}\text { Pregnancy } \\
\text { Outcome }\end{array}$ \\
\hline 1 & 28 & $18 w+6$ & XO & $\begin{array}{l}\text { (1) neck water cysts; ( } 2 \text { ) whole body edema; (3) bilateral } \\
\text { pleural effusion, ascites. }\end{array}$ & TOP \\
\hline 2 & 28 & $18 w+1$ & XO & $\begin{array}{l}\text { Fetal femur diameter is smaller than gestational age. The } \\
\text { fetal umbilical cord is wrapped around the neck. }\end{array}$ & TOP \\
\hline 3 & 37 & $18 w+2$ & $\mathrm{~T} 21$ & $\begin{array}{l}\text { (1) nasal bone is not shown; ( } 2 \text { ) possible complete } \\
\text { endocardial pad defect; ( } 3 \text { ) middle finger phalanx is not } \\
\text { shown. }\end{array}$ & TOP \\
\hline 4 & 32 & $18 w+1$ & $\mathrm{~T} 21$ & $\begin{array}{l}\text { Possible T21: (1) the middle phalanx of the left little finger is } \\
\text { not shown, the phalanx in the right little finger is punctate } \\
\text { calcification; (2) the ventricular septal defect (possible } \\
\text { malformation); (3) the nasal bone dysplasia; (4) the flap } \\
\text { angle is increased; (5) the right foot is changed like a "shoe } \\
\text { foot". }\end{array}$ & TOP \\
\hline 5 & 28 & $19 w+4$ & $\mathrm{~T} 21$ & $\begin{array}{l}\text { Possible T21: (1) nasal bone is not shown; (2) Increased flap } \\
\text { angle; (3) thickening of liver parenchyma; (4) widening of } \\
\text { umbilical vein ventral section; (5) abdominal circumference, } \\
\text { femoral diameter and humeral diameter is smaller than } \\
\text { gestational age; 6) abnormal intracardiac structure. }\end{array}$ & TOP \\
\hline 6 & 36 & $17 w+4$ & $\mathrm{~T} 21$ & $\begin{array}{l}\text { Possible T21: (1) nasal bone is not shown; (2) increased flap } \\
\text { angle; (3) the little finger phalanx of the hands is not shown; } \\
\text { (4) the multiple echoes in the abdominal cavity; (5) abnormal } \\
\text { intracardiac structure. }\end{array}$ & TOP \\
\hline 7 & 24 & $21 w+4$ & T21 & $\begin{array}{l}\text { Possible T21: (1) "double bubble sign" in the abdominal } \\
\text { cavity; (2) fetal nasal bone loss; (3) liver echo thickening; (4) } \\
\text { bilateral femur and tibia less than - } 2 \text { standard deviation; (5) } \\
\text { increased flap angle; (6) abnormal intracardiac structure. }\end{array}$ & TOP \\
\hline 8 & 34 & $19 w+3$ & $\mathrm{~T} 21$ & NA & TOP \\
\hline 9 & 36 & 18 & $\mathrm{~T} 21$ & NA & TOP \\
\hline 10 & 30 & $20+$ & $\mathrm{T} 21$ & NA & TOP \\
\hline 11 & 43 & 13 & $\mathrm{~T} 21$ & NA & TOP \\
\hline 12 & 30 & $18 w+6$ & $\mathrm{~T} 18$ & $\begin{array}{l}\text { Possible T18: (1) the left cleft lip (degree III) and splitting. (2) } \\
\text { ventricular septal defect. (3) Possible right hand overlap. (4) } \\
\text { "strawberry" head. }\end{array}$ & TOP \\
\hline 13 & 39 & $17 w+5$ & T18 & $\begin{array}{l}\text { Possible T18: (1) no-leaf full forebrain malformation; (2) fetal } \\
\text { central cleft lip (degree III) with cleft palate; (3) nasal bone is } \\
\text { not seen; (4) narrow eye distance; (5) middle finger phalanx of } \\
\text { both hands is not shown; (6) abnormal cardiac structure. }\end{array}$ & TOP \\
\hline 14 & 35 & $14 w+6$ & $\mathrm{~T} 13$ & $\begin{array}{l}\text { Possible T13: (1) forebrain non-cracking malformation; (2) } \\
\text { narrow eye distance; (3) strong echogenic plaque in bilateral } \\
\text { eyeballs; (4) median cleft lip (class III), cleft palate; (5) slightly } \\
\text { enhanced echogenicity of both kidney parenchyma; (6) } \\
\text { abnormal intracardiac structure Possible; (7) poor appetite } \\
\text { filling; (8) multiple strong echogenic spots in the abdominal } \\
\text { cavity. }\end{array}$ & TOP \\
\hline
\end{tabular}

Note: T21: trisomy 21, T18: trisomy $18, \mathrm{~T} 13$, trisomy $13, \mathrm{NT}$ : Nuchal translucency, NA: not available. 


\begin{tabular}{|llllll|}
\hline CaselD & Age & $\begin{array}{l}\text { Gestational } \\
\text { week }\end{array}$ & $\begin{array}{l}\text { expanded } \\
\text { NIPT } \\
\text { Result }\end{array}$ & Abnormal ultrasound Result & $\begin{array}{l}\text { Pregnancy } \\
\text { Outcome }\end{array}$ \\
\hline 15 & 40 & $19 w+3$ & T13 & $\begin{array}{l}(1) \text { narrow eye distance, single nostril; (2) fetal intracardiac } \\
\text { structural abnormalities; (3) multi-finger after both hands; } \\
\text { enhanced bowel echo. }\end{array}$ & TOP \\
\hline 16 & 39 & 12 & T21 & Fetal demise & TOP \\
\hline 17 & 38 & 16 & T18 & NA & TOP \\
\hline 18 & 38 & $17 w+1$ & XXY & Fetal cleft lip and alveolar cleft & TOP \\
\hline 19 & 43 & $13 w+1$ & T13 & Intrauterine single fetus, NT 1.07MM & TOP \\
\hline Note: T21: trisomy $21, T 18:$ trisomy 18, T13, trisomy 13, NT: Nuchal translucency, NA: not available. & \\
\hline
\end{tabular}

\section{Expanded Nipt Test Results For Rats And Cnvs}

54 RATs cases and 33 CNVs cases were reported among the 24,736 cases. Of the 54 RATs cases, Trisomy 8 (T8), Trisomy 14 (T14), Trisomy 16 (T16) were the top three frequent RATs, with frequencies of $16.7 \%(9 / 54), 13 \%$ (7/54) and 13\% (7/54) respectively (Supplementary Fig. 1). 30 RATs women underwent amniocenteses, three cases of T14, Trisomy 22 (T22) and Trisomy 6(T6) were confirmed by karyotyping analysis and the other 27 cases had normal karyotype results. Of the 27 discordant cases, 1 case lost pregnancy, due to fetal demise. 17 pregnant women had normal live births with normal neonatal examination results and physical appearance at the time of postnatal follow-up. The other 9 cases were lost to follow-up (Fig. 2). 21 RATs cases refused to take amniocenteses, 1 case directly chose TOP, 2 cases lost pregnancies, due to fetal demise. 18 pregnant women had normal live births with normal neonatal examination results and physical appearance at the time of postnatal follow-up (Fig. 2).

16 cases of the 33 CNVs underwent CMA tests, while others refused confirmatory diagnostic tests. 8 CNVs of the 16 cases underwent confirmatory testing and were concordant with CMA results (Table S1), 6 cases underwent TOP and 2 cases had normal live births. 8 cases showed normal result in CMA analysis and 6 cases had normal live births. Among the 17 cases without an invasive diagnostic testing, 12 had normal live births and 5 cases were lost to contact (Fig. 2).

\section{Low-risk Expanded Nipt Test Results}

Of the 24,169 low-risk cases, $76.25 \%(18,429 / 24,169)$ cases were successfully followed-up. 100 cases underwent diagnostic tests, due to anxiety and pressure. 18,329 cases didn't have amniocenteses tests, 5740 cases were lost to contact. Among the 100 cases with diagnostic test results, 88 cases showed normal karyotype results and gave normal births and 8 women chose TOP, because of fetal anatomical anomalies detected by ultrasound. One false negative case of T18 and three abnormalities in chromosome 3 (CMA, 3p26.3p25.3[61,891 - 10,914,685] x1), 13 (Karyotyping analysis, 46,XN,r(13)(p12q34) [69]/45,XY,-13[7]/46,XY,dic r(13;13)(p12q34;p12q34)[2]), 22 (CMA, 22q13.2q13.33[44,088,529 - 51,197,766]x1) were diagnosed and the four cases terminated their pregnancies (Fig. 3). In the 18,329 cases who had low-risk results and didn't receive diagnostic testing, 18,028 had normal live births, 90 lost pregnancy, 89 decided to undergo TOP because of aberrant fetal ultrasound results, 21 had stillbirths and 101 reported unknown fetal abnormalities (Fig. 3).

\section{Performance Of Expanded Nipt Test}

On the basis of the expanded NIPT test results and the pregnancy outcome data available, we analyzed the performance of the expanded NIPT test in the detection of common aneuploidies, SCAs, RATs and CNVs (Table 3). For T21, T18, and T13, the 
sensitivity was $98.61 \%, 90.91 \%$ and $100 \%$; specificity was $99.91 \%, 99.95 \%$ and $99.87 \%$; positive predictive value (PPV) was 89.87\%, 76.92\% and 27.27\%; negative predictive value (NPV) was 99.99\%, 99.98\% and 100\% respectively. Expanded NIPT detected SCAs, RATs and CNVs with PPVs of $57.39 \%, 10 \%$ and $50 \%$ respectively based on the data we have. Notably, The PPV for individual SCAs was as follows: 45, XO 19.61\% (10/51), 47, XXX 75\% (9/12), 47, XXY 79.41\% (27/34) and 47, XYY 77.78\% $(14 / 18)$ (Table 3). When stratified by CNV size, expanded NIPT detected eight cases whose CNVs size was greater than $10 \mathrm{Mb}$ and eight samples whose CNVs size was less than $10 \mathrm{Mb}$. The PPV for individual CNVs $>10 \mathrm{Mb}$ was $62.5 \%$, but the performance decreased to $42.86 \%$ when the size of CNVs was smaller than $10 \mathrm{Mb}$ (Table 3).

Table 3

The performance of expanded NIPT in screening for trisomies 21, 18, 13, SCAs, RATs and CNVs

\begin{tabular}{|c|c|c|c|c|c|c|c|c|}
\hline $\begin{array}{l}\text { expanded } \\
\text { NIPT test }\end{array}$ & TP & FP & $\mathrm{TN}$ & FN & $\begin{array}{l}\text { Sensitivity } \\
(95 \% \mathrm{Cl})\end{array}$ & $\begin{array}{l}\text { Specificity } \\
(95 \% \mathrm{Cl})\end{array}$ & $\begin{array}{l}\text { PPV } \\
(95 \% \mathrm{Cl})\end{array}$ & $\begin{array}{l}\text { NPV } \\
(95 \% \mathrm{Cl})\end{array}$ \\
\hline $\mathrm{T} 21$ & 142 & 16 & 18359 & 2 & $\begin{array}{l}98.61 \% \\
(95.07 \%-99.83 \%)\end{array}$ & $\begin{array}{l}99.91 \% \\
(99.86 \%-99.95 \%)\end{array}$ & $\begin{array}{l}89.87 \% \\
(84.46 \%-93.54 \%)\end{array}$ & $\begin{array}{l}99.99 \% \\
(99.96 \%-100.00 \%)\end{array}$ \\
\hline T18 & 30 & 9 & 18477 & 3 & $\begin{array}{l}90.91 \% \\
(75.67 \%-98.08 \%)\end{array}$ & $\begin{array}{l}\text { 99.95\%(99.91\%- } \\
99.98 \%)\end{array}$ & $\begin{array}{l}76.92 \% \\
(63.23 \%-86.60 \%)\end{array}$ & $\begin{array}{l}99.98 \% \\
(99.95 \%-99.99 \%)\end{array}$ \\
\hline T13 & 9 & 24 & 18486 & 0 & $\begin{array}{l}100 \%(66.37 \%- \\
100.00 \%)\end{array}$ & $\begin{array}{l}99.87 \% \\
(99.81 \%-99.92 \%)\end{array}$ & $\begin{array}{l}27.27 \% \\
(20.09 \%-35.87 \%)\end{array}$ & $100.00 \%$ \\
\hline SCAs & 66 & 49 & & & & & $57.39 \%$ & \\
\hline $45, X 0$ & 10 & 41 & - & - & & & $19.61 \%$ & \\
\hline $47, X X X$ & 9 & 3 & & & & & $75 \%$ & \\
\hline $47, X X Y$ & 27 & 7 & & & & & $79.41 \%$ & \\
\hline $47, X Y Y$ & 14 & 4 & & & & & $77.78 \%$ & \\
\hline RATs & 3 & 27 & - & - & & & $10 \%$ & \\
\hline CNVs & 8 & 8 & - & - & & & $50 \%$ & \\
\hline $\begin{array}{l}\text { CNVs } \\
(<10 \mathrm{M})\end{array}$ & 3 & 4 & & & & & $42.86 \%$ & \\
\hline $\begin{array}{l}\text { CNVs } \\
(>10 M)\end{array}$ & 5 & 4 & & & & & $62.5 \%$ & \\
\hline
\end{tabular}

\section{Comparison Of Prenatal Diagnosis Willingness And Pregnancy Outcomes}

Of 267 women at high risk for common aneuploidies, 230 women (86.14\%) accepted the invasive prenatal diagnosis, 37 women (13.86\%) rejected the diagnosis for various reasons, such as severe ultrasound abnormalities, concerns about abortion, etc. As shown in Table 4 and Fig. 4,the rate of prenatal diagnosis for women with positive results of common fetal aneuploidies was significantly higher than those with positive results of SCAs $(64.25 \%, 64 / 115)$, RATs $(55.56 \%, 24 / 54)$ and CNVs $(48.48 \%, 16 / 33)$ (fisher's exact test, $\mathrm{P}<0.05$ for all cases). While no significant difference in the rate of invasive prenatal diagnosis was observed among the women at high risk for SCAs, RATs and CNVs (fisher's exact test, P > 0.05 for all cases). $99.45 \%(180 / 181)$ of the women carrying fetuses with $\mathrm{T} 21 / \mathrm{T} 18 / \mathrm{T} 13$ terminated their pregnancy, which was significantly 
higher than those positive for SCAs $(38.46 \%, 10 / 26)$, and CNVs $(75 \%, 6 / 8)$ (fisher's exact test, $\mathrm{P}<0.05$ for all cases). Women carrying fetuses with $47, \mathrm{XYY}$ and CNVs ( $<10 \mathrm{M})$ were more willing to continue their pregnancy (Table 4 and Fig. 4).

Table 4

Comparison of prenatal diagnosis willingness and clinical treatment

\begin{tabular}{|c|c|c|c|c|c|c|}
\hline Group & $\begin{array}{l}\text { Number of } \\
\text { positive cases }\end{array}$ & $\begin{array}{l}\text { Accepted } \\
\text { diagnosis }\end{array}$ & $\begin{array}{l}\text { Rejected } \\
\text { diagnosis }\end{array}$ & $\begin{array}{l}\text { Number of } \\
\text { confirmed cases }\end{array}$ & $\begin{array}{l}\text { Terminate } \\
\text { pregnancy }\end{array}$ & $\begin{array}{l}\text { Continue } \\
\text { pregnancy }\end{array}$ \\
\hline $\begin{array}{l}\text { Common } \\
\text { aneuploidies }\end{array}$ & 267 & $230(86.14 \%)$ & $37(13.86 \%)$ & 181 & $180(72.87 \%)$ & $1(8.1 \%)$ \\
\hline T21 & 178 & 158(88.76\%) & $20(11.24 \%)$ & 142 & 141(99.3\%) & $1(0.7 \%)$ \\
\hline T18 & 51 & $39(76.47 \%)$ & $12(23.53 \%)$ & 30 & $30(100 \%)$ & 0 \\
\hline T13 & 38 & $33(86.84 \%)$ & $5(13.16 \%)$ & 9 & $9(100 \%)$ & 0 \\
\hline Fetal SCAs & $179 * \star \star$ & $115(64.25 \%)$ & 64(35.75\%) & 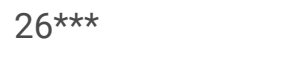 & $10(38.46 \%)$ & $16(61.54 \%)$ \\
\hline $45, \times 0$ & $82^{\star \star \star}$ & $51(62.2 \%)$ & $31(37.8 \%)$ & $5^{\star \star \star *}$ & $2(40 \%)$ & $3(60 \%)$ \\
\hline $47, X X X$ & $25^{\star \star \star}$ & $12(48 \%)$ & $13(52 \%)$ & $3^{\star \star *}$ & 1(33.33\%) & $2(66.67 \%)$ \\
\hline $47, X X Y$ & $48^{*}$ & $34(70.83 \%)$ & $14(29.17 \%)$ & $11^{\star \star \star}$ & $6(54.55 \%)$ & $5(45.45 \%)$ \\
\hline $47, X Y Y$ & 24 & $18(75 \%)$ & $6(25 \%)$ & $7 * \star \star$ & $1(14.29 \%)$ & 6(85.71\%) \\
\hline RATs & $54^{\star \star \star}$ & $30(55.56 \%)$ & $24(44.44 \%)$ & 3 & NA & NA \\
\hline CNVs & $33^{\star \star \star}$ & $16(48.48 \%)$ & $17(51.52 \%)$ & $8 * \star *$ & $6(75 \%)$ & $2(25 \%)$ \\
\hline CNVs (<10M) & $12^{*}$ & 7(58.33\%) & $5(41.67 \%)$ & $3^{\star \star \star}$ & 1(33.33\%) & $2(66.67 \%)$ \\
\hline $\mathrm{CNVs}(>10 \mathrm{M})$ & $21^{\star \star \star}$ & $9(42.86 \%)$ & $12(57.14 \%)$ & 5 & $5(100 \%)$ & 0 \\
\hline
\end{tabular}

\section{Discussion}

In this study, 24,768 pregnant women were enrolled to investigate the clinical performance of the expanded NIPT test. The sensitivity and specificity of expanded NIPT test was over $99 \%$ for trisomies 21,18 and 13 , which was consistent with previous studies [7-11]. Our results presented a comparable PPV for T21 and T18 but a relatively low PPV for T13 compared to other studies $[7,13]$. This could be because of the small number of T13-positive cases in our study, the difference in the number of T13 cases would increase the variation of PPV. Only $1.1 \%(267 / 24,736)$ of cases were classified as high-risk for common aneuploidies and needed to undergo diagnostic karyotyping analysis. The application of expanded NIPT tests avoided the implementation of more than $98 \%$ of invasive diagnostic procedures and reduced unnecessary fetal losses caused by invasive tests. The miscarriage rates were $1.4 \%$ after amniocentesis and $1.9 \%$ after chorionic villus sampling [14].Therefore, the test is a safe screening tool with high cost efficiency. In $35.85 \%$ (19/53) cases with unconfirmed high-risk expanded NIPT results, fetal anatomical anomalies were reported by regular ultrasound examination, these women underwent TOPs based on the abnormal ultrasound results. Ultrasound examination revealed 4 suspicious T21, 2 suspicious T18 and 1 suspicious T13 in the 19 cases. These results demonstrated that the number of true positive cases might be underestimated in this study.

In our study, expanded NIPT detected SCAs with a PPV of 57.4\%, which is similar with Porreco's study [15] but much lower than the results reported by other studies [4,5]. The difference is to large extent attributable to the different analytical techniques used in the studies. Unlike the z-scores algorithm used in our study and Porreco's study [15], Mazloom constructed a classification algorithm for SCA detection and determined the accuracy of the classification algorithm on another 
independent cohort of maternal samples [4]. Hooks et al developed a chromosome-selective approach and devised a risk algorithm incorporating fetal fraction to evaluate the risk for SCAs [5]. In our study, expanded NIPT more accurately detected triple $X, X X Y$ and $X Y Y$ syndrome than $X O$ syndrome, which is in line with that reported by others $[13,16,17]$. The difference in the detection of different SCAs might be attributed to two main reasons. Firstly, there are 58 homologous genes on $X$ and $Y$ chromosome, 29 genes are located at the ends of sex chromosomes. The sequencing length of expanded NIPT is as short as 36 bases, therefore, an error in sequencing these homologous genes might easily occur on $X$ and $Y$ chromosomes [16]; Secondly, $\mathrm{X}$ chromosome mosaicism is another contributing maternal factor to the difference in pregnant women [18].

In recent years, the expanded NIPT test has been applied to the screening for other chromosomal abnormalities including fetal RATs and CNVs $[19,20]$, however, the application of this expanded screening is still under debate in clinical settings. In our clinical practice, the PPV was as low as $10 \%$ for the detection of RATs and $50 \%$ for the detection of CNVs. By comparing the set of CNVs with the Online Mendelian Inheritance in Man database, 6 CNVs cases were pathogenic and 3 CNVs were unknown (Table S1). The results suggested the screening test was capable of successfully detecting fetal RATs and CNVs, but caused a large fraction of false-positive cases. Previous studies have claimed benefits [21]; however, we suggest that expanded NIPT hasn't demonstrated a sufficiently high true-positive rate in the detection of RATs and CNVs, particularly for RATs. Therefore, the application of expanded NIPT to screening for RATs and CNVs must be balanced with the miscarriage risk of using diagnostic testing due to the procedure itself.

In this study, in comparison to the women with positive results for positive SCA, RAT and CNV results, the rate of prenatal diagnosis for women with positive T21/T18/T13 results was significantly increased. These findings were in line with the Zhou's study [12]. The compliance of pregnant women was better because they know more about these three diseases. Due to the seriousness of the diseases, most pregnant women are willing to undergo prenatal diagnosis and almost all of the positive cases will terminate their pregnancy in China. Zhou's study reported women positive for Turner syndrome were more willing to continue their pregnancies, while we found women carrying fetuses with 47, XYY tended to continue their pregnancies, while women with other fetal SCAs were more likely to underdo TOP. Women with confirmed larger CNVs (> 10M) showed higher TOP rate than those with confirmed smaller CNVs $(<10 \mathrm{M})$. These differences may have been related to the level of prenatal genetic counseling, the cognition level of pregnant women, economic situation, etc.

In conclusion, our study demonstrates that the expanded NIPT test detects fetal trisomies 21,18 and 13 with high sensitivity and specificity but shows a relatively low true positive value for SCAs, RATs and CNVs determination. The application of expanded NIPT to the detection of SCAs, RATs and CNVs, particularly RATs, should be considered with caution. With a positive expanded NIPT result, the women at high risk for common trisomies are more willing to take invasive prenatal diagnosis and terminate their pregnancies. Therefore, it is critical to improve the accuracy of expanded NIPT technology on the detection of SCAs, RATs and CNVs and set up a precious genetic counseling protocol for those expanded NIPT-positive cases.

\title{
Methods And Materials
}

\section{Ethics statement and sample collection}

24,768 participants were recruited in the study from the Women and Children's Hospital from January 2013 to April 2019 in Xiamen of Fujian province, China. All the participants provided written inform consent. This study followed strictly confidentiality regulations on privacy protection and was approved by the Institutional Review Board of the Women and Children's Hospital (KY-2019-037). Five milliliters of peripheral blood were taken from the pregnant woman and stored in Streck Cell Free DNA BCT ® blood collection tube (Streck, La Vista, Nebraska, United States) and plasma DNA were extracted within four days after collection.

\section{Sequencing And Bioinformatics Analysis}

\author{
Page 8/16
}


Details of the expanded NIPT methods have been published previously [22]. In brief, plasma was separated by sequential centrifugations of the blood sample at $1600 \mathrm{~g}$ at $4{ }^{\circ} \mathrm{C}$ for $10 \mathrm{~min}$. Cell-free DNA was extracted from plasma and subjected to library construction. The quantity and quality of the library were examined by real-time polymerase chain reaction and size distribution analysis. Only qualified library was sequenced, and the data generated were analyzed using bioinformatics algorithms to detect trisomy 21 (T21), T18, T13, sex chromosomal aneuploidies (SCAs), rare autosomal aneuploidies (RATs) and large copy number variations (CNVs) as previously described [23].

\section{Validation Of High-risk Screening Results}

Each participant paid CNY1400 ( USD178) to take the expanded NIPT test in the Women and Children's Hospital. For those participants who received high-risk results of T21, T18, T13, SCAs, RATs, they were recommended to take confirmatory invasive tests using amniocentesis, followed by karyotyping analysis. For those CNVs-positive cases, chromosomal microarray analysis (CMA) was performed for validation. Prenatal diagnosis was carried out according to our routine experimental method and completed in our prenatal diagnosis center. The costs of diagnostic tests were covered by an insurance. Moreover, CNY400,000 ( USD50,990) would be paid for those women who had confirmed false negative results of T21, T13 and T18 as compensation. However, the insurance didn't cover the false negative results of SCAs, RATs and CNVs cases in the Women and Children's Hospital.

\section{Clinical Follow-up Analysis}

Routine prenatal care was recommended for participants who had low-risk screening results in expanded NIPT tests. Ultrasound examination was performed regularly to detect fetal abnormalities. If abnormal fetal anomalies were observed, participants were suggested to take genetic counselling. Some participants chose termination of pregnancy (TOP). For the other participants, a postnatal follow-up was conducted by telephone interview at 3 months after birth. The following information was collected, including the ultrasound examination report, final pregnancy outcomes, baby's gender and newborn physical examination. Pregnancies who had high-risk expanded NIPT results of T21, T18, T13, SCAs, RATs and CNVs were recommended for diagnostic tests using amniocentesis. The "true positive" and "false positive" referred to the high-risk expanded NIPT results that were concordant or discordant with diagnostic genetic testing respectively. The "true negative" cases were low-risk in the expanded NIPT test and validated by normal neonatal physical examination except for SCAs or diagnostic test analysis. The "false negative" referred to those cases who were reported to be aneuploidy-negative but present an aneuploidy karyotype which was validated by invasive genetic testing. Notably, the "true positive" and "false positive" CNVs were validated by the gold-standard CMA analysis. Participants who had high-risk screening results but didn't have confirmatory diagnostic results were excluded in the evaluation of the performance of expanded NIPT in screening for T21, T18, T13, SCAs, RATs and CNVs. Loss to follow-up referred to cases who were unreachable or rejected to be interviewed.

\section{Statistical analysis}

The data were analyzed using R3.2.0 (http://www.R-project.org).Differences in categorical variables were compared between two groups using fisher exact test, and $P$ values $\leq 0.05$ was considered as statistically significant.

\section{Abbreviations}

Expanded noninvasive prenatal test

expanded NIPT

Trisomy 21

T21

Trisomy 18

T18

Trisomy 13 
T13

Sex chromosomal aneuploidies

SCAs

Rare autosomal aneuploidies

RATs

Copy number variations

CNVs

Termination of pregnancy

TOP

Chromosomal microarray analysis

CMA

True positive

TP

True negative

TN

Positive predictive value

PPV

Negative predictive value

NPV

Nuchal translucency

NT.

\section{Declarations}

\section{Ethics approval and consent to participate}

All the participants provided written inform consent. This study followed strictly confidentiality regulations on privacy protection and approved by the Institutional Review Board of the Women and Children's Hospital (KY-2019-037).

\section{Consent for publication}

All the participants provided written inform consent.

\section{Availability of data and materials}

All data generated or analyzed during this study are included in this published article and its supplementary files.

\section{Competing interests}

The authors declare there is no competing interests.

\section{Funding}

None 


\section{Authors' contributions}

Yulin Zhou designed and directed the study. and Jia Li, Meihua Tan,Wei Li performed the sequencing experiment and bioinformatic analysis. Yunsheng Ge, Jian Zhang Yanru Huang and Jiayan Chen conducted genetic counselling, validation of expanded NIPT results and follow-up of high-risk participants. Pi-lin Sung gave professional advice on the writing and revision of the manuscript.

\section{Acknowledgement}

None

\section{References}

1. Agarwal A, Sayres LC, Cho MK, Cook-Deegan R, Chandrasekharan S. Commercial landscape of noninvasive prenatal testing in the United States. Prenat Diagn. 2013;33:521-31.

2. Benn P, Cuckle H, Pergament E. Non-invasive prenatal testing for aneuploidy: Current status and future prospects. Ultrasound Obstet Gynecol. 2013;42:15-33.

3. Chen EZ, Chiu RWK, Sun H, Akolekar R, Chan KCA, Leung TY, et al. Noninvasive prenatal diagnosis of fetal trisomy 18 and trisomy 13 by maternal plasma dna sequencing. PLoS One. 2011;6:1-7.

4. Mazloom AR, Džakula Ž, Oeth P, Wang H, Jensen T, Tynan J, et al. Noninvasive prenatal detection of sex chromosomal aneuploidies by sequencing circulating cell-free DNA from maternal plasma. Prenat Diagn. 2013;33:591-7.

5. Hooks J, Wolfberg AJ, Wang ET, Struble CA, Zahn J, Juneau K, et al. Non-invasive risk assessment of fetal sex chromosome aneuploidy through directed analysis and incorporation of fetal fraction. Prenat Diagn. 2014;34:496-9.

6. Samango-Sprouse C, Banjevic M, Ryan A, Sigurjonsson S, Zimmermann B, Hill M, et al. SNP-based non-invasive prenatal testing detects sex chromosome aneuploidies with high accuracy. Prenat Diagn. 2013;33:643-9.

7. Zhang H, Gao Y, Jiang F, Fu M, Yuan Y, Guo Y, et al. Non-invasive prenatal testing for trisomies 21, 18 and 13: clinical experience from 146958 pregnancies. Ultrasound Obstet Gynecol. 2015;45:530-8.

8. Chitty LS, Wright D, Hill M, Verhoef TI, Daley R, Lewis C, et al. Uptake, outcomes, and costs of implementing non-invasive prenatal testing for down syndrome into NHS maternity care: Prospective cohort study in eight diverse maternity units. Obstet Gynecol Surv. 2016;71:637-9.

9. Dan S, Wang W, Ren J, Li Y, Hu H, Xu Z, et al. Clinical application of massively parallel sequencing-based prenatal noninvasive fetal trisomy test for trisomies 21 and 18 in 11105 pregnancies with mixed risk factors. Prenat Diagn. 2012;32:1225-32.

10. Gil MM, Quezada MS, Bregant B, Ferraro M, Nicolaides KH. Implementation of maternal blood cell-free DNA testing in early screening for aneuploidies. Ultrasound Obstet Gynecol. 2013;42:34-40.

11. Beamon CJ, Hardisty EE, Harris SC, Vora NL. A single center's experience with noninvasive prenatal testing. Genet Med. 2014;16:681-7.

12. Zhou Q, Zhu Z-P, Zhang B, Yu B, Cai Z-M, Yuan P. Clinical features and pregnancy outcomes of women with abnormal cell-free fetal DNA test results. Ann Transl Med. 2019;7:317-7.

13. Petersen AK, Cheung SW, Smith JL, Bi W, Ward PA, Peacock S, et al. Positive predictive value estimates for cell-free noninvasive prenatal screening from data of a large referral genetic diagnostic laboratory. Am J Obstet Gynecol. 2017;217:691.e1-691.e6. doi:.

14. Tabor A, Vestergaard CHF. Lidegaard. Fetal loss rate after chorionic villus sampling and amniocentesis: An 11-year national registry study. Ultrasound Obstet Gynecol. 2009;34:19-24. 
15. Porreco RP, Garite TJ, Maurel K, Marusiak B, Ehrich M, Van Den Boom D, et al. Noninvasive prenatal screening for fetal trisomies $21,18,13$ and the common sex chromosome aneuploidies from maternal blood using massively parallel genomic sequencing of DNA. Am J Obstet Gynecol. 2014;211:365.e1. . doi:10.1016/j.ajog.2014.03.042.

16. Deng C, Zhu Q, Liu S, Liu J, Bai T, Jing X, et al. Clinical application of noninvasive prenatal screening for sex chromosome aneuploidies in 50,301 pregnancies: initial experience in a Chinese hospital. Sci Rep. 2019;9:1-8. doi:.

17. Zhang B, Lu BY, Yu B, Zheng FX, Zhou Q, Chen YP, et al. Noninvasive prenatal screening for fetal common sex chromosome aneuploidies from maternal blood. J Int Med Res. 2017;45:621-30.

18. Wang L, Meng Q, Tang X, Yin T, Zhang J, Yang S, et al. Maternal mosaicism of sex chromosome causes discordant sex chromosomal aneuploidies associated with noninvasive prenatal testing. Taiwan J Obstet Gynecol. 2015;54:527-31.

19. Pertile MD, Halks-Miller M, Flowers N, Barbacioru C, Kinnings SL, Vavrek D, et al. Rare autosomal trisomies, revealed by maternal plasma DNA sequencing, suggest increased risk of feto-placental disease. Sci Transl Med. 2017;9:1-12.

20. Benn P, Grati FR. Genome-wide non-invasive prenatal screening for all cytogenetically visible imbalances. Ultrasound Obstet Gynecol. 2018;51:429-33.

21. Snyder MW, Simmons LE, Kitzman JO, Coe BP, Henson JM, Daza RM, et al. Copy-Number Variation and False Positive Prenatal Aneuploidy Screening Results. N Engl J Med. 2015;:1-7. doi:.

22. Article 0 . A method for noninvasive detection of fetal large deletions/ duplications by low coverage massively parallel sequencing. Prenat Diagn. 2013;33:584-90.

23. Ha G, Roth A, Lai D. Integrative analysis of genome-wide loss of heterozygosity and mono-allelic expression at nucleotide resolution reveals disrupted pathways in triple negative breast cancer Integrative analysis of genome-wide loss of heterozygosity and mono-allelic express. Genome Res. 2012;:1995-2007.

\section{Figures}




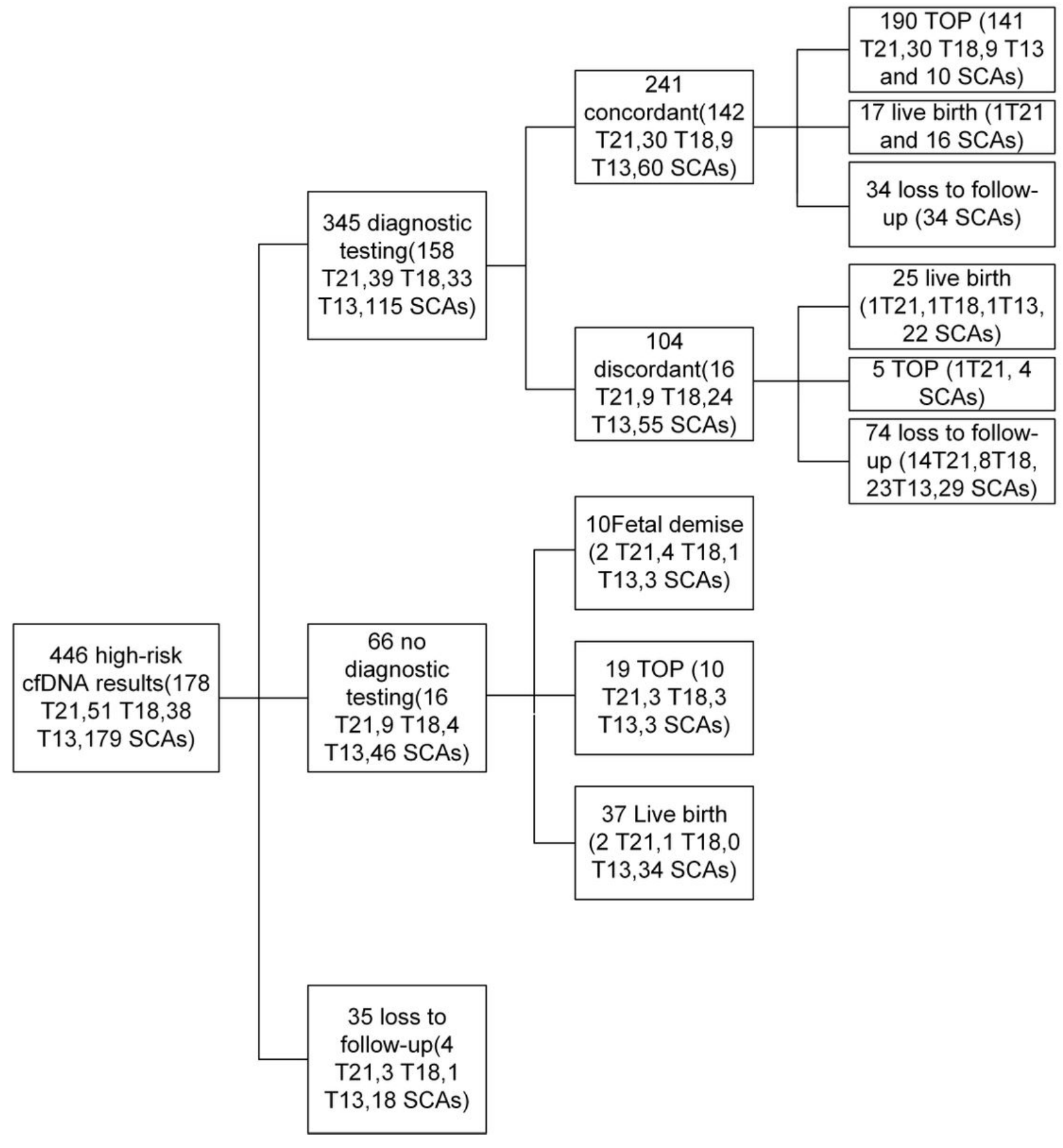

Figure 1

Detailed clinical outcome results for the cases high rick for common aneuploidies, SCAs. T21: trisomy 21, T18: trisomy 18, T13: trisomy 13, SCAs: sex chromosomal aneuploidies, TOP: termination of pregnancy 


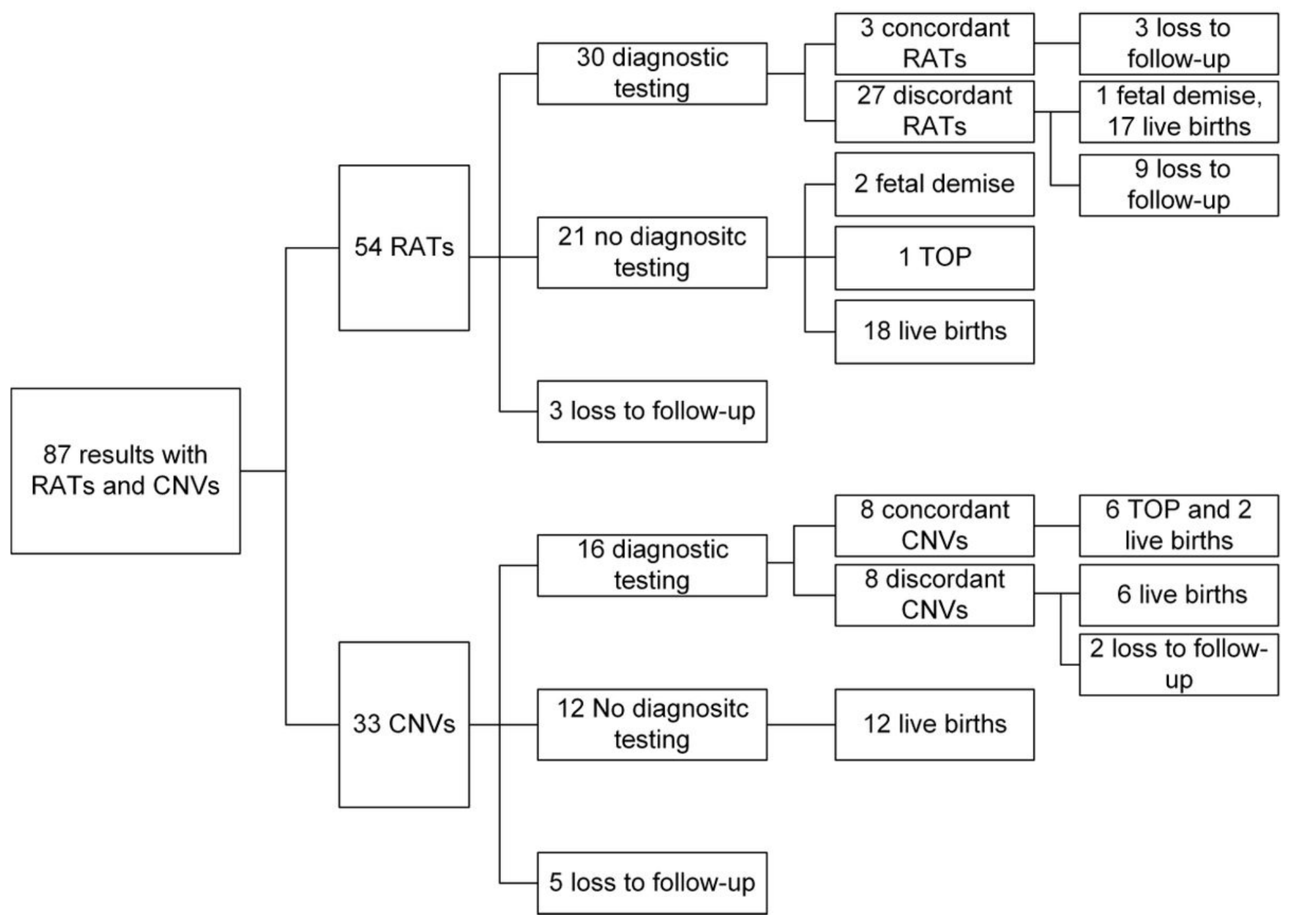

Figure 2

Detailed clinical outcome results of RATs and CNVs cases from expanded NIPT tests. RATs: rare autosomal aneuploidies, CNVs: copy number variations 


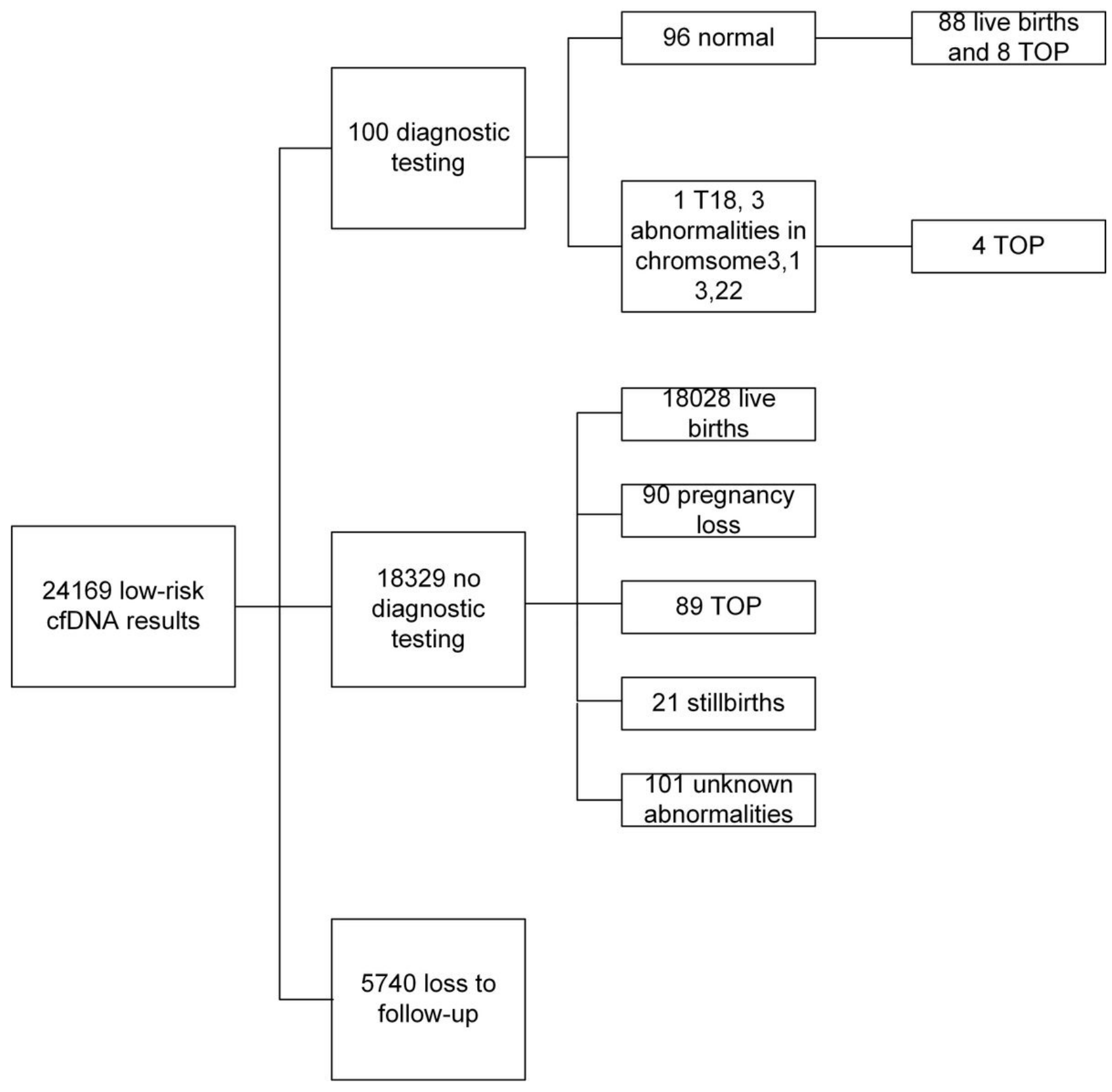

Figure 3

Detailed clinical outcome results of low-risk expanded NIPT test results 
A
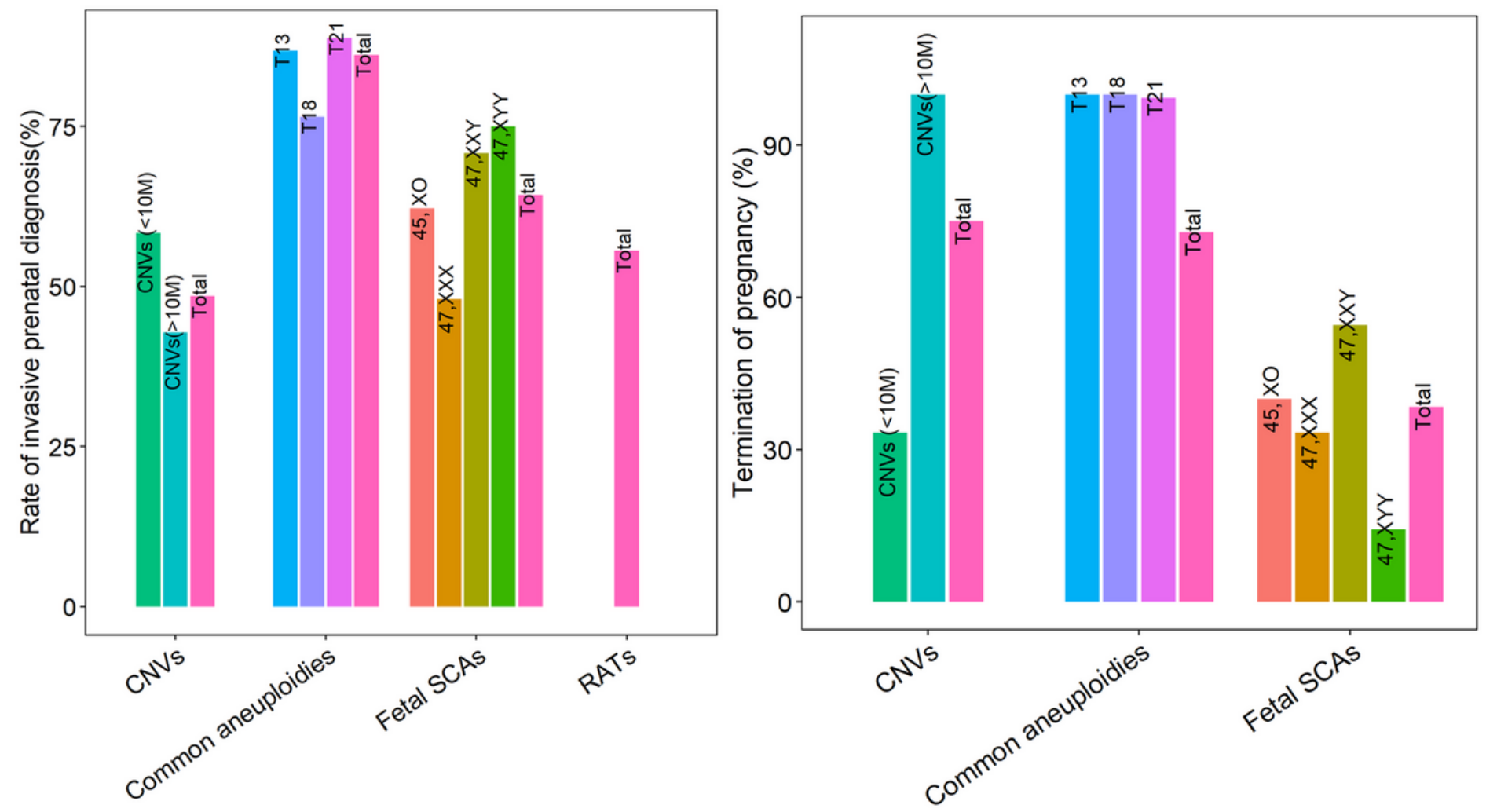

Figure 4

Comparison of prenatal diagnosis willingness and pregnancy outcomes. A. The rate of prenatal diagnosis for different women with expanded NIPT positive results. B. The rate of termination of pregnancy for different women with expanded NIPT positive results

\section{Supplementary Files}

This is a list of supplementary files associated with this preprint. Click to download.

- SupplementaryFigure1.tiff

- Supplementarytables.docx 